\title{
Comparison of Ovulation Induction with Letrozole with Metformin Versus Letrozole Alone in Females Presenting with Polycystic Ovarian Syndrome
}

\section{Zubda Aiman, ${ }^{1}$ Amna Khanam, ${ }^{2}$ Mahliqa Maqsood, ${ }^{3}$ Mehwish ayyaz, ${ }^{4}$ Alia, ${ }^{5}$ Tayyaba Kanwal ${ }^{6}$}

\begin{abstract}
Objective: To compare the frequency of Ovulation Induction after administration of Letrozole with metformin versus Letrozole alone in females presenting with Polycystic Ovarian Syndrome

Methods: This Randomized Controlled Trial was done in unit 5 of Lady Aitchison Hospital Lahore for 6 months. Total 200 females fulfilling the inclusion criteria were recruited from OPD. Lottery method was used for randomization of study subjects. Females in group A were given Letrozole $2.5 \mathrm{mg}$ once a day for five days (from third to seventh day)of the cycle for three consecutive months and metformin $1500 \mathrm{mg}(500 \mathrm{mg} 3$ times a day) daily for three months, while females in group B were given Letrozole $2.5 \mathrm{mg}$ once a day for five days (from third to seventh day) le for three consecutive months. Then they were followed up in OPD for 3 cycles. In all 3 cycles TVS was done on day 12 to access the number of follicles and to measure the size of largest follicle, and on day 21 of cycle progesterone level will be assessed for confirmation of ovulation induction. The data was entered and analyzed through SPSS version 20. Mean and standard deviation was calculated for age and BMI. Frequency and percentage was calculated for Ovulation induction. Both groups were compared by using chi-square test taking $\mathrm{p}$-value $<0.05$ as significant. Data was stratified for BMI (Normal, overweight and Obese).After stratification chi-square test was applied keeping a $p$ value $\leq 0.05$ as significant.

Results: In Group-A mean age of women was $28.18 \pm 6.58$ years. In Group-B mean age of women was $27.08 \pm 5.15$ years. In Group-A ovulation induction rate was much higher as compared to that of Group-B women. i.e. $(89 \%$ vs. $60 \%)$. p-value $=0.000$. Ovulation induction rate was significantly higher with Letrozole+ Metformin in women who were having normal BMI, overweight \& obese as compared to that of Letrozole alone.

Conclusion: Letrozole with metformin is more effective for the ovulation Induction females presenting with polycystic ovarian Syndrome as compared to letrozole alone.()

Key Words: Polycystic Ovarian Syndrome, Management, Ovulation Induction, Letrozole, Metformin

How to Cite: Aiman Z, Khanam A, Maqsood M, Ayyaz M, Alia, Kanwal K. Comparison of ovulation induction with letrozole with metformin versus letrozole alone in females presenting with polycystic ovarian syndrome. Esculapio.2020;16(04):54-58.

DOI: https://doi.org/10.51273/esc20.2516412
\end{abstract}

\section{Introduction}

DCO is commonest hormonal disorder of females in reproductive age group and it has very high prevalence. ${ }^{1}$ PCOS is the leading cause of anovulatory subfertility and it accounts for $70 \%$ of

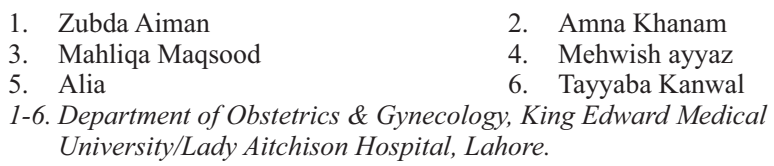
Gynaecology, King Edward Medical University/Lady Aitchison Hospital, Lahore,Pakistan.Email: zubdaiman@gmail.com

$\begin{array}{ll}\text { Submission Date: } & 16-11-2020 \\ \text { 1st Revision Date: } & 17-11-2020 \\ \text { Acceptance Date: } & 11-12-2020\end{array}$

subfertility cases related to ovulatory disorder. 5$10 \%$ women of reproductive age group are affected by PCOS. ${ }^{4}$

The cause of this multifactorial condition is not completely known and its phenotype expression varies. Clomiphene citrate (CC) is frequently used drug for ovulation induction. But one fourth of women do not give adequate response to this drug. These resistant cases are typically treated with administration of gonadotrophins but there are more chances of multifetal gestations and hyperstimulation of ovaries. ${ }^{5}$

Recently it has been found that Letrozole makes endometrium more receptive for implantation in addition to increasing ovulation rate therefore chances of 
success-ful pregnancy have increased in women presenting with this disorder. ${ }^{6}$ Additional benefits of Letrozole are decreased number of multifetal gestations and less androgenic side effects and decreased cases of ovarian hyperstimulation so less frequent monitoring is required as compared to gonadotrophins. $^{7}$

PCOS is heterogenous disorder involving genetic, hormonal and environmental factors. No definitive treatment is available for this condition. Weight reduction and lifestyle modification is mainstay of the treatment. ${ }^{8}$ First case of PCOS was recognised in 1721 in Italy.

Studies in different countries show prevalence of PCOS using Rotterdam criteria as follows, $6.3 \%$ in Srilanka, $2 \%$ in south China, $5 \%$ in Thailand, $8 \%$ in UK and $4 \%$ in USA(there is no difference among black and white women). ${ }^{2}$

Literature has reported that letrozole is effective in ovulation induction but there are conflicting results reported in literature. Moreover, there are no study conducted which compares letrozole in combination with metformin and letrozole alone and local magnitudes are also missing. Through this study we wanted to get local magnitudes and results which can be applicable and on the basis of which we can implement the use of letrozole with metformin for management of PCO instead of letrozole alone. Objective of this study is to compare the frequency of Ovulation Induction after administration of Letrozole with metformin versus Letrozole alone in females presenting with Polycystic Ovarian Syndrome. Hypothesis of the study was that there is some difference in frequency of Ovulation Induction with Letrozole with metformin versus letrozole alone in females presenting with Polycystic Ovarian Syndrome.

\section{Methods}

This randomized controlled trial was done in Unit 5 of Lady Aitchison Hospital in 6 months time. Total of 200 cases (100 cases in each group was calculated with $80 \%$ power of test, $5 \%$ level of significance and taking expected percentage of ovulation induction i.e. $90.57 \%$ with Letrozole with metformin and $60.78 \%$ with Letrozole alone in females presenting with PCOs) were enrolled by Non-Probability, consecutive Sampling. Women age 18-39 years, BMI $<35$, Infertility due to anovulation, Polycystic Ovarian Syndrome (fulfilling two of the following three crite- ria atleast:Oligomenorrhea / amenorrhea, Hyper androgenaemia (testosterone $\geq 2.5 \mathrm{nmol} / 1$ ) or free androgen index $\geq 5$ or clinical evidence (acne/hirsutism), Ultrasound evidence of Polycystic Ovarian Syndrome (either $\geq 12$ follicle measuring $2-9 \mathrm{~mm}$ in dia meter or ovarian volume $>10 \mathrm{ml})$ ), Normal husband semen analysis (sperm count 20 million $/ \mathrm{ml}, 60 \%$ are motile and $30 \%$ have normal morphology), Patency of both fallopian tubes by hysteroscopy and laproscopy, and No recent treatment within six months for induction of ovulation on history were included. Ovulation induction was measured as production of follicles confirmed on Ultrasonographic findings (follicles size $>18 \mathrm{~mm}$ at 12 day of menstruation) and day 21 progestrone level $>3 \mathrm{ng} / \mathrm{dl}$ for three cycles, if these findings were achieved then labelled as ovulation induction. Women with Uterine pathology by ultrasound, Hyperprolactinemia (<500mIU/1), Hyperthyroidism $(\mathrm{TSH}<0.5 \mathrm{Uu} / \mathrm{ml}) /$ Hypothyroidism $(\mathrm{TSH}>6 \mathrm{Uu} / \mathrm{ml}), \mathrm{FSH}>9 \mathrm{mIU} / \mathrm{mn}$ (during early follicular phase), Previous surgery related to genital tract, Impaired hepatic (serum bilirubin level $>2 \mathrm{mg} / \mathrm{dl}$ )/ impaired renal functions (serum creatinine $>1 \mathrm{mg} / \mathrm{dl}$ ), Diabetes Miletus / BSR>140mg/dl were excluded.

After taking permission from instituitional review board/head of department, 200 females who are fit in the inclusion criteria were recruited from Outpatient department of Lady Aitchison Hospital Lahore. Informed consent and personal information (name, age, BMI and contact) was obtained. Lottery method was used for randomization. Females of both groups were counseled about dietary modification and encouraged to do brisk walk for 30 min twice a day. Females in group A were given Letrozole 2.5mg once a day for five days (from third to seventh day)of cycle for three months and metformin $1500 \mathrm{mg}$ (500mg 3 times a day) daily for three months, while females in group B were given Letrozole $2.5 \mathrm{mg}$ once a day for five days (from third to seventh day of cycle) for three consecutive months. Then they were followed up in OPD for 3 cycles. In all 3 cycles TVS was done on day 12 to access the number of follicles and to measure the size of largest follicle, and on day 21 of cycle progesterone level will be assessed for confirmation of ovulation induction. All the data was collected according to predesigned proforma. The data was entered and analyzed through SPSS version 20. Mean and standard deviation was calcu-lated for age and BMI. 
Frequency and percentage was calculated for Ovulation induction. Both groups were compared by using chi-square test taking p-value $<0.05$ as significant. Data was stratified for BMI (Normal, overweight and Obese). After stratification chisquare test was applied keeping a $p$ value $\leq 0.05$ as significant.

\section{Results}

In Group-A mean age of women was $28.18 \pm 6.58$ years. In Group-B mean age of women was $27.08 \pm$ 5.15 years. In Group-A minimum and maximum age of women was 18 and 39 years while in Group-B this was 18 and 37 years respectively. (Table-1)

In Group-A mean BMI of women was $28.05 \pm 2.82$. In Group-B mean BMI of women was $27.54 \pm 2.54 \mathrm{Kg} /$ $\mathrm{m}^{2}$. In Group-A minimum and maximum BMI of women was 23 and 32 while in Group-B this was 23 and 31.9 respectively. As per body mass index criteria in Group-A 20(20\%) women were having normal BMI, 44(44\%) were overweight and 36(36\%) were obese. In Group-B 20 (20\%) women were having normal weight, 59(59\%) were overweight and $21(21 \%)$ were obese. In Group-A ovulation induction rate was much higher as compared to that of Group-B women. i.e. $(89 \%$ vs. $60 \%$ ). p-value $=0.000$ (Table-2)

Ovulation induction rate was much higher with Letrozzole+ Metformin in women who were having normal BMI, overweight \& obese as compared to that of Letrozzole alone i.e. Group-A (Ovulation induction Rate): Normal BMI Women: 95\% vs. Group-B: $65 \%$ (pvalue $=0.018$ ), Over Weight Women: GroupA: $86.4 \%$ vs. $55.9 \%$ (p-value $=0.001) \&$ Obese women: Group-A: $88.9 \%$ vs. Group-B:66.7\% (p-value $=$ 0.040). (Table-3)

\section{Discussion}

PCOS is responsible for $75 \%$ cases of ovulatory disorders. . PCOS-related subfertility is treated appropriately by ovulation induction. Many treatment modalities including medical and surgical options have been employedto treat PCOS linked infertility. Medical options include Metformin, Clomiphene citrate, Letrozole and gonadotrophins. ${ }^{10}$ Surgical options include ovarian drilling and wedge resection. Resistant cases to both medical and surgical treatments are offered Intrauterine insemination with stimulated cycle and In-vitro fertilization. ${ }^{11}$

About half of all women with PCOS show some
Table 1: Age Distribution Of Patients

\begin{tabular}{ccc}
\hline & Group-A & Group-B \\
\hline n & $\mathbf{1 0 0}$ & $\mathbf{1 0 0}$ \\
Mean & 28.18 & 27.08 \\
SD & 6.585 & 5.154 \\
Minimum & 18 & 18 \\
Maximum & 39 & 37 \\
\hline
\end{tabular}

Group-A= Letrozole + Metformin

Group-B= Letrozole

Table 2: Ovulation Induction In Study Groups

\begin{tabular}{cccr|}
\hline Ovulation Induction & Group-A & Group-B & Total \\
\hline Yes & $89(89 \%)$ & $60(60 \%)$ & $\mathbf{1 4 9}$ \\
No & $11(11 \%)$ & $40(40 \%)$ & $\mathbf{5 1}$ \\
Total & 100 & 100 & $\mathbf{2 0 0}$ \\
\hline
\end{tabular}

Chi-Square Test $=22.13 \quad$ p-value $=0.000$

Table 3: Ovulation Induction In Study Groups Stratified For Bmi

\begin{tabular}{lcccc}
\hline \multicolumn{1}{c}{ BMI } & $\begin{array}{c}\text { Ovulation } \\
\text { Induction }\end{array}$ & Group-A & Group-B & p-value \\
\hline Normal & Yes & $19(95 \%)$ & $13(65 \%)$ & $\mathbf{0 . 0 1 8}$ \\
& No & $1(5 \%)$ & $7(35 \%)$ & \\
Overweight & Yes & $38(86.4 \%)$ & $33(55.9 \%)$ & $\mathbf{0 . 0 0 1}$ \\
& No & $6(13.6 \%)$ & $26(44.1 \%)$ & \\
Obese & Yes & $32(88.9 \%)$ & $14(66.7 \%)$ & $\mathbf{0 . 0 4 0}$ \\
& No & $4(11.1 \%)$ & $7(33.3 \%)$ & \\
\hline
\end{tabular}

degree of insulin resistance. Hyperinsulinemia ultimately leads to the hyperandrogenism, which is responsible for the clinical manifestation of disease. 77 Metformin increases insulin sensitivity and inturn decreases the production of androgens from ovaries, also improves quality of the egg and induces ovulation. However several studies showed that the combination of metformin plus Clomiphene Citrate in the CC-resistant patients was very effective in inducing ovulation in $68.6 \%-77.7 \%$ of patients. 78 $80 .^{12}$

Several case reports have shown the effective role of metformin in PCOS patients by enhancing conception rate and improving the metabolic profile. ${ }^{13}$

Clomiphene citrate does not give equal response in all patients for ovulation induction. It acts by antagonising the effects of estrogen and thus causes raised levels of gonadotrophins from pituitary gland, this in turn will stimulate growth of ovarian follicles and ovulation. $^{14}$

Letrozole inhibits actions of enzyme aromatase. It blocks the conversion of androgens to estrogens in ovarian follicles, this will result in fall in circulating 
level of estrogen and rise in intraovarian androgens, this decreased level of estrogen inturn causes negative effect on hypothalamic-pituitary thus raising FSH level and it will enhance ovarian follicular development. ${ }^{15}$ The effective role of letrozole in patients with clomiphene-resistant PCOS has been documented with the use of $2.5 \mathrm{mg}$ daily doses on third to seventh day of menstrual cycle in various studies. ${ }^{16}$

In this study it was observed that women who were given Letrozole + Metformin among them rate of ovulation was $89 \%$ as compared to the women who were given Letrozole among them rate of ovulation induction was $60 \%$. A statistically significant association was seen between ovulation induction with treatment groups. $(\mathrm{p}$-value $=0.000) .{ }^{17}$

Davar reported that with the use of Metformin+ letrozole as combination showed pregnancy rate per cycle in $8 \%$ women. Nahid L in his study reported an induction rate of $88 \%$ with the use of letrozole alone. Hatem Abu Hashim from Egypt reported rate of ovulation induction as $64.9 \%$ with the use of letrozole alone. Badawy et al. who had an ovulatory rate of $62 \%$ for letrozole cycles. ${ }^{90}$ In other trials, Mitwally and Casper $^{91}$ had ovulatory rate of $75 \%$, Al-Omari et al. had an ovulatory rate of $87.5 \%$, whereas Elnashar et al. reported an ovulation rate of $54.6 \%$.

Sohrabvand et al. added either CC or letrozole initially after 6-8 weeks of treatment with metformint in CC-resistant PCOS women, they found that the combination of metformin plus letrozole leads to more pregnancies. About $15-40 \%$ of women with PCOS have $\mathrm{CC}$ resistance which can be ascribed to the antiestrogenic effect of $\mathrm{CC}$ on endometrium and cervical mucus or by hypersecretion of luteinizing hormone.

Although administration of Letrozole for induction of ovulation varies in many studies but overall Letrozole alone is effective in PCOS women. It is widely used for many years and various studies have proved its beneficial role for ovulation induction. In addition to it, it does not have adverse effect on endometrium and cervical mucus. ${ }^{18}$

In literature only one study was found who had used combination of these both treatment in PCOS women. Ibrahim Abd Elgafo in his study used metformin plus letrozole and reported an ovulation rate of $48.9 \%$. To our knowledge, no studies have yet compared the effects of letrozole with combined metformin. ${ }^{19}$

This study is the first of its kind in our set up and in local literature which both these drugs have been used in combination. However different studies have used letrozole with $\mathrm{CC} .^{20}$ But no such combination was adopted by studies done previously to see the efficacy of these two combination for successful outcome in women with PCOS. ${ }^{16}$

\section{Conclusion}

Letrozole with metformin is more effective for the ovulation Induction in females presenting with polycystic ovarian syndrome as compared to letrozole alone.

\section{Conflict of Interest: $\quad$ None}

\section{References}

1. Rosenfield RL, Ehrmann DA. The pathogenesis of polycystic ovary syndrome (PCOS): the hypothesis of PCOS as functional ovarian hyperandrogenism revisited. Endocrine reviews. 2016;37(5):467-520.

2. Sirmans SM, Pate KA. Epidemiology, diagnosis, and management of polycystic ovary syndrome. Clinical epidemiology. 2014;6:1.

3. Sohrabvand F, Ansari S, Bagheri M. Efficacy of combined metformin-letrozole in comparison with metformin-clomiphene citrate in clomiphene-resistant infertile women with polycystic ovarian disease. Human reproduction. 2006;21(6):1432-5.

4. Fauser BC, Tarlatzis BC, Rebar RW, Legro RS, Balen $\mathrm{AH}$, Lobo R, et al. Consensus on women's health aspects of polycystic ovary syndrome (PCOS): the Amsterdam ESHRE/ASRM-Sponsored 3rd PCOS Consensus Workshop Group. Fertility and sterility. 2012;97(1):28-38. e25.

5. Mohammad MB, Seghinsara AM. Polycystic ovary syndrome (PCOS), diagnostic criteria, and AMH. Asian Pacific journal of cancer prevention: APJCP. 2017;18(1):17.

6. Cortínez A, De Carvalho I, Vantman D, Gabler F, Iñiguez $\mathrm{G}$, Vega M. Hormonal profile and endometrial morphology in letrozole-controlled ovarian hyperstimulation in ovulatory infertile patients. Fertility and sterility. 2005;83(1):110-5.

7. Rajan RK, Balaji B. Soy isoflavones exert beneficial effects on letrozole-induced rat polycystic ovary syndrome (PCOS) model through anti-androgenic mechanism. Pharmaceutical biology. 2017; 55(1): 242- 51.

8. Moran LJ, Hutchison SK, Norman RJ, Teede HJ. Lifestyle changes in women with polycystic ovary syndrome. Cochrane Database of Systematic Reviews. 2011(7). 
9. Sidra S, Tariq MH, Farrukh MJ, Mohsin M. Evaluation of clinical manifestations, health risks, and quality of life among women with polycystic ovary syndrome. PloS one. 2019;14(10):e0223329.

10. Arain F, Arif N, Halepota H. Frequency and outcome of treatment in polycystic ovaries related infertility. Pakistan journal of medical sciences. 2015;31(3): 694.

11. Group TEA-SPCW. Consensus on infertility treatment related to polycystic ovary syndrome. Human reproduction. 2008;23(3):462-77.

12. Diamanti-Kandarakis E, Dunaif A. Insulin resistance and the polycystic ovary syndrome revisited: an update on mechanisms and implications. Endocrine reviews. 2012;33(6):981-1030.

13. Glueck CJ, Wang P, Goldenberg N, Sieve-Smith L. Pregnancy outcomes among women with polycystic ovary syndrome treated with metformin. Human Reproduction. 2002;17(11):2858-64.

14. Palomba S, Pasquali R, Orio Jr F, Nestler JE. Clomiphene citrate, metformin or both as first-step approach in treating anovulatory infertility in patients with polycystic ovary syndrome (PCOS): a systematic review of head-to-head randomized controlled studies and meta-analysis.Clinical endocrinology. 2009; 70(2):311-21.

15. Casper RF, MITWALLY MF. Use of the aromatase inhibitor letrozole for ovulation induction in women with polycystic ovarian syndrome. Clinical obstetrics and gynecology. 2011;54(4):685-95.
16. He D, Jiang F. Meta-analysis of letrozole versus clomiphene citrate in polycystic ovary syndrome. Reproductive biomedicine online. 2011;23(1):91-6.

17. Kim J, Lim W, Kim E-K, Kim M-K, Paik N-S, Jeong $\mathrm{S}-\mathrm{S}$, et al. Phase II randomized trial of neoadjuvant metformin plus letrozole versus placebo plus letrozole for estrogen receptor positive postmenopausal breast cancer (METEOR). BMC cancer. 2014; 14(1): $1-5$.

18. Kelley ST, Skarra DV, Rivera AJ, Thackray VG. The gut microbiome is altered in a letrozole-induced mouse model of polycystic ovary syndrome. PloS one. 2016;11(1):e0146509.

19. Badawy A, Aal IA, Abulatta M. Clomiphene citrate or letrozole for ovulation induction in women with polycystic ovarian syndrome: a prospective randomized trial. Fertility and sterility. 2009;92(3):849-52.

20. Roque M, Tostes AC, Valle M, Sampaio M, Geber S. Letrozole versus clomiphene citrate in polycystic ovary syndrome: systematic review and meta-analysis. Gynecological Endocrinology. 2015;31(12):91721.
Authors Contribution
AZ: Concept, Design, analysis
KA: Analysis, Interpretation
MM: Interpretation
AM: Drafting Revising, Analysis
A: Analysis and Interpretation
KT: Design, Interpretation 